\title{
Depletion of mitochondrial reactive oxygen species downregulates epithelial-to-mesenchymal transition in cervical cancer cells
}

\author{
Galina Shagieva', Lidiya Domnina ${ }^{1}$, Olga Makarevich², Boris Chernyak ${ }^{3}$, Vladimir \\ Skulachev $^{3,4}$, Vera Dugina $^{1}$ \\ ${ }^{1}$ Department of Mathematical Methods in Biology, Belozersky Research Institute of Physico-Chemical Biology, Lomonosov \\ Moscow State University, Moscow, Russia \\ ${ }^{2}$ Faculty of Basic Medicine, Lomonosov Moscow State University, Moscow, Russia \\ ${ }^{3}$ Department of Bioenergetics, Belozersky Research Institute of Physico-Chemical Biology, Lomonosov Moscow State \\ University, Moscow, Russia \\ ${ }^{4}$ Faculty of Bioengineering and Bioinformatics, Lomonosov Moscow State University, Moscow, Russia \\ Correspondence to: Galina Shagieva, email: gshagieva@genebee.msu.su \\ Keywords: epithelial-to-mesenchymal transition, mitochondrial reactive oxygen species, ERK1/2, cervical cancer cells, SkQ1 \\ Received: July 22, $2016 \quad$ Accepted: November 14, $2016 \quad$ Published: November 25, 2016
}

\section{ABSTRACT}

In the course of cancer progression, epithelial cells often acquire morphological and functional characteristics of mesenchymal cells, a process known as epithelial-tomesenchymal transition (EMT). EMT provides epithelial cells with migratory, invasive, and stem cell capabilities. Reactive oxygen species produced by mitochondria (mtROS) could be of special importance for pro-tumorigenic signaling and EMT.

In our study, we used mitochondria-targeted antioxidant SkQ1 to lower the mtROS level and analyze their role in the regulation of the actin cytoskeleton, adhesion junctions, and signaling pathways critical for tumorigenesis of cervical carcinomas. A decrease in mtROS was found to induce formation of $\beta$-cytoplasmic actin stress fibers and circumferential rings in cervical cancer SiHa and Ca-Ski cells. It was accompanied by an upregulation of $\mathrm{E}$-cadherin in $\mathrm{SiHa}$ cells and a downregulation of $\mathrm{N}$-cadherin in Ca-Ski cells. In SiHa cells, an increase in E-cadherin expression was accompanied by a reduction of Snail, E-cadherin negative regulator. A stimulation of mtROS by epidermal growth factor (EGF) caused a Snail upregulation in SiHa cells that could be downregulated by SkQ1. SkQ1 caused a decrease in activation of extracellular-signalregulated kinases 1 and 2 (ERK1/2) in SiHa and Ca-Ski. EGF produced an opposite effect. Incubation with SkQ1 suppressed EGF-induced p-ERK1/2 upregulation in SiHa, but not in Ca-Ski cells. Thus, we showed that scavenging of mtROS by SkQ1 initiated reversal of EMT and suppressed proliferation of cervical cancer cells.

\section{INTRODUCTION}

Functioning of epithelial tissues requires stable intercellular contacts and cell polarity. Strict tissue organization is lost in epithelial tumors. Tumor epithelial cells usually discard basoapical polarity and reorganize cytoskeleton and adhesion junctions to acquire morphological and functional characteristics of mesenchymal cells. This process is known as EMT $[1,2]$. EMT is a fundamental process involved in the regulation of embryonic development during morphogenesis, but it also plays a role in tumor progression and organ fibrosis [3-5]. EMT molecular changes include a downregulation of epithelial markers, such as E-cadherin, alpha-catenin and keratins, as well as a rise in expression of mesenchymal proteins $\mathrm{N}$-cadherin and vimentin. EMT helps cells to become mobile. EMT endues cells with migratory, invasive, and stem cell capabilities [6, 7]. Escaping from the epithelial environment allows oncogene-expressing cells to proliferate and evolve [8].

The role of reactive oxygen species (ROS) and redox homeostasis in tumor progression is controversial. ROS are involved in the anticancer control mechanisms, apoptosis and cellular senescence. Most of the modern 
anticancer therapies rely on the ROS-induced killing of tumor cells, but this strategy results in strong side effects in normal tissues. On the other hand, the level of ROS is usually higher in malignant cells [9], and elevated ROS stimulate tumor cell proliferation, motility, and pro-survival signaling pathways contributing to tumorigenesis. Nevertheless, several clinical trials failed to show beneficial effects of dietary antioxidant supplements in primary cancer prevention and therapy [10]. This failure might be due to low efficiency of antioxidants in scavenging of the specific ROS responsible for tumorigenic signaling. Antioxidants can impede the intrinsic anticancer defense (apoptosis and cell senescence) as well as the effectivity of chemotherapy. Recent reports on the stimulation of melanoma metastases by antioxidants $[11,12]$ aroused wide public concern.

Targeting antioxidants to mitochondria is a promising approach since mtROS could be of special importance for pro-tumorigenic signaling [13]. Gene knockdown of MnSOD (mitochondrial superoxide dismutase isoform) resulted in mesenchymal-to-epithelial transition in aggressive breast cancer cell lines while induced MnSOD expression promoted EMT phenotype. The authors suggested that EMT was promoted by hydrogen peroxide produced by MnSOD in mitochondria [14]. An additional benefit of the mitochondria-targeted antioxidants based on lipophilic cations comes from a possible selective accumulation of these compounds in tumor cells. This phenomenon was described for the lipophilic cationic fluorescent probe Rhodamine 123 in 1982 [15], confirmed later for other cationic compounds, but still remains unexplained.

The first attempt to analyze the effect of mitochondriatargeted antioxidants on tumorigenesis was reported by our laboratory [16]. The efficient mitochondria-targeted antioxidant SkQ1 [17] suppressed a spontaneous tumor (predominantly lymphomas) development in homozygous p53 knockout mice and inhibited the growth of human colon carcinoma HCT116/p53 $3^{-1-}$ xenografts in athymic mice [16]. In vitro studies demonstrated that $\mathrm{SkQ} 1$ reversed the morphological transformation of Ras- and SV40-transformed p53 $3^{--}$fibroblasts and HCT116/p53 $3^{-/}$cells [16]. A similar action (both in vivo and in vitro) of the antioxidant $\mathrm{N}$-acetylL-cysteine (NAC) at more than 1,000,000 times higher doses indicated that the effects of SkQ1 were due to mtROS scavenging. Several mitochondria-targeted antioxidants designed as conjugates of triphenylphosphonium cation $\left(\mathrm{TPP}^{+}\right)$with nitroxides (Mito-CP, Mito-TEMPO) $[18,19]$ or a vitamin E analog (Mito-Vitamin-E) [21], also inhibited the tumor cell proliferation in vitro and the growth of tumor xenografts in vivo. Mito-CP acetamide (Mito-CP-Ac), an analog of Mito-CP containing $\mathrm{TPP}^{+}$lacking the antioxidant activity, also inhibited proliferation of several tumor cell lines via an undiscovered mechanism [22]. A conjugate of $\mathrm{TPP}^{+}$with ubiquinol (MitoQ) [23], the pioneering mitochondria-targeted antioxidant, inhibited proliferation of two breast cancer cell lines, but worked as a pro-oxidant, as revealed by the activation of $\mathrm{Nrf} 2$, a master regulator of the cellular response to oxidative stress [24].

In the present study we used SkQ1 to control mtROS and analyze their role in the regulation of the actin cytoskeleton, adhesion junctions and signaling pathways critical for the tumorigenesis of cervical carcinomas.

\section{RESULTS}

\section{SkQ1 treatment changed actin cytoskeleton organization and proliferation in cervical cancer cells}

The loss of epithelial phenotype by cells during EMT is connected with cytoskeleton rearrangement. Non-muscle $\beta$ and $\gamma$-actins are ubiquitously expressed in almost all human cells $[24,25]$. Amount and distribution of two cytoplasmic actins - $\beta$-cytoplasmic actin ( $\beta$-actin hereafter) and $\gamma$-cytoplasmic actin $(\gamma$-actin hereafter) are different in cancer and normal epithelial cells [27]. Cytoplasmic actins are organized in different cytoskeletal structures and connected to distinct cell junctions. $\beta$-Actin is predominant in stress fibers, circular bundles, contractile mitotic rings, and adhesion junctions (AJ). $\gamma$-Actin is connected to tight junctions [28] and is organized in cortical and lamellar networks [29].

$\mathrm{HaCaT}$ are spontaneously transformed immortal keratinocytes from histologically normal adult human skin. $\mathrm{HaCaT}$ cells are polygonal in shape, form islands in culture and are similar to normal epithelial cells. Nevertheless $\mathrm{HaCaT}$ cells are aneuploid [30] and have mutations in TP53, tumor suppressor gene [31]. We used $\mathrm{HaCaT}$ as non-tumorigenic control line since (i) these cells were neither tumorigenic after subcutaneous injection nor invasive in a more sensitive transplantation assay [30], (ii) $\mathrm{HaCaT}$ transplants growing on glutaraldehyde-fixed collagen gels reconstituted an almost perfect epithelium with an increasing transition from ortho- to parakeratotic stratum corneum (containing nuclear remnants), which occurs normally in the epithelium of true mucous membrane of mouth and vagina [30], (iii) $\mathrm{HaCaT}$ cells were derived from the stratified squamous epithelium, just as cervical cancer cells did. In $\mathrm{HaCaT}$ cells $\beta$-actin was distributed diffusely in the cytoplasm, organized in circumferential rings at the peripheral cell area, and formed a network in the free lamellas. Incubation with SkQ1 ( $40 \mathrm{nM}, 3$ days) did not change general actin cytoskeleton organization but slightly influenced $\beta$-actin at the zone of free lamellas in HaCaT cells (Figure 1A).

We used two human cervical cancer cell lines$\mathrm{SiHa}$ and $\mathrm{Ca}-\mathrm{Ski}$ cells that represent different stages of a cancer progression. SiHa cells were obtained from a primary tumor while Ca-Ski cells were derived from a cervical carcinoma metastasis. Morphology of SiHa cells was heterogeneous; there were cells of both spindlelike and scattered types in the culture. Ca-Ski cells were mostly of scattered morphology. In both cancer cell lines $\beta$-actin was distributed diffusely in the cytoplasm and 
concentrated in lamellas and lamellipodia (Figure 1A). As a result of incubation with SkQ1, stress fibers and circumferential $\beta$-actin rings were formed. Dense $\gamma$-actin apical network did not change in $\mathrm{HaCaT}$ and $\mathrm{SiHa}$ cells after SkQ1 treatment. In Ca-Ski cells, SkQ1 stimulated a redistribution of $\gamma$-actin to the periphery (Figure 1B).
Treatment with SkQ1 decreased SiHa cell motility in the Transwell assay (Figure 1C).

SkQ1 suppressed proliferation of SiHa cells, while proliferation of non-malignant $\mathrm{HaCaT}$ cells was not affected (Figure 1D). Antioxidant NAC (5mM) inhibited $\mathrm{SiHa}$ and HaCaT cells growth while structurally related
A
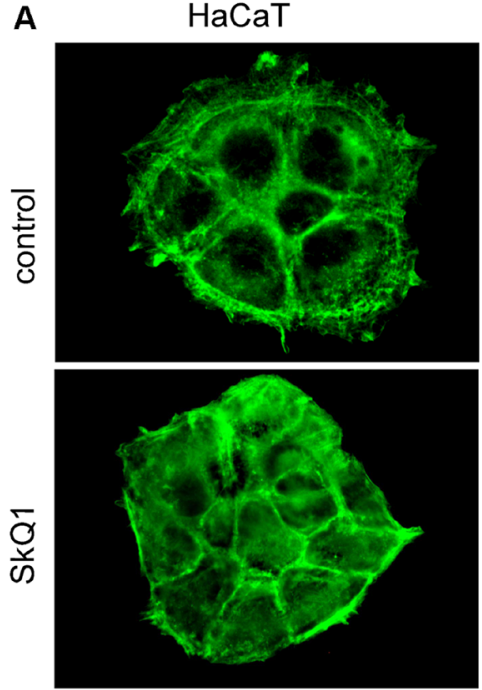

B
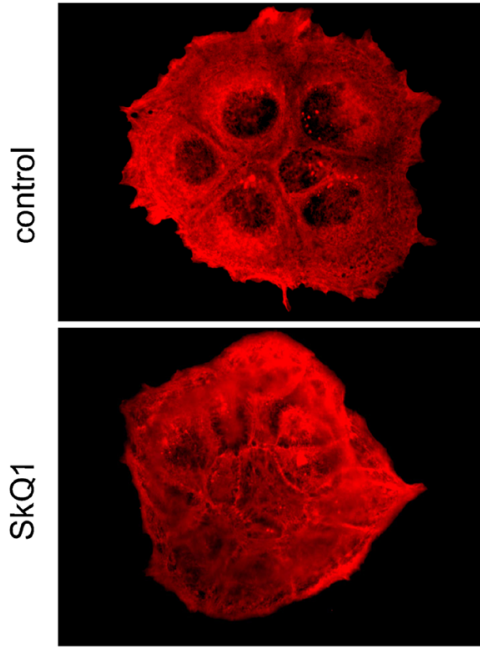

C

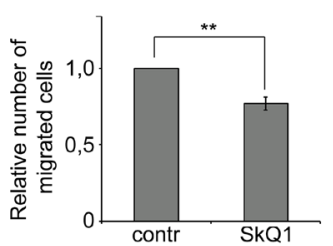

D
$\mathrm{SiHa}$
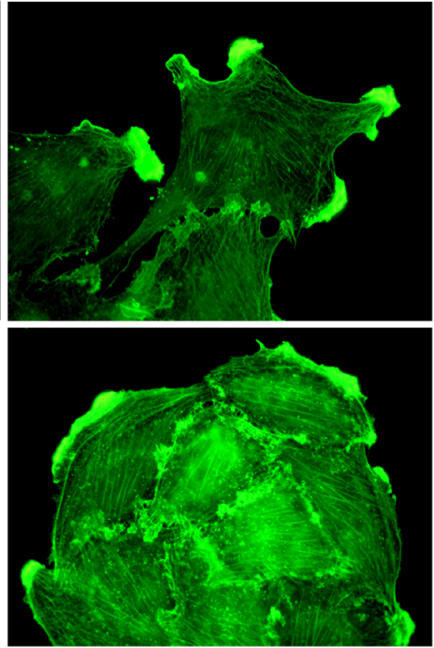

$\mathrm{SiHa}$
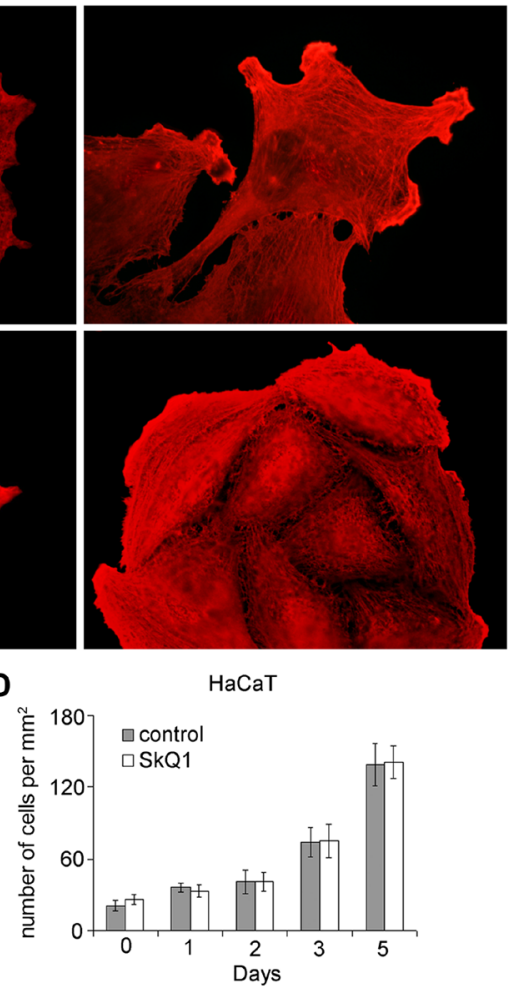

Ca-Ski
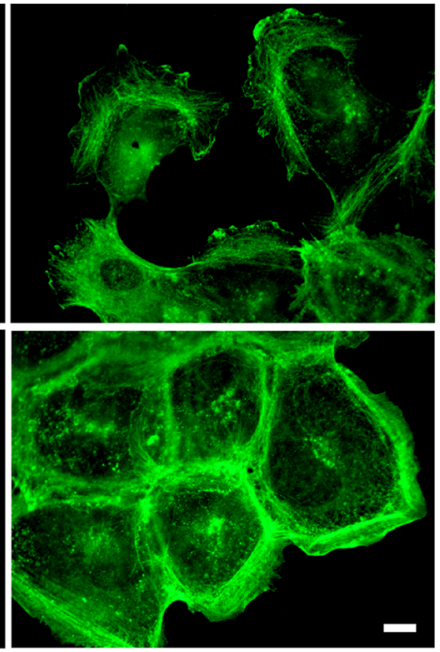

Ca-Ski
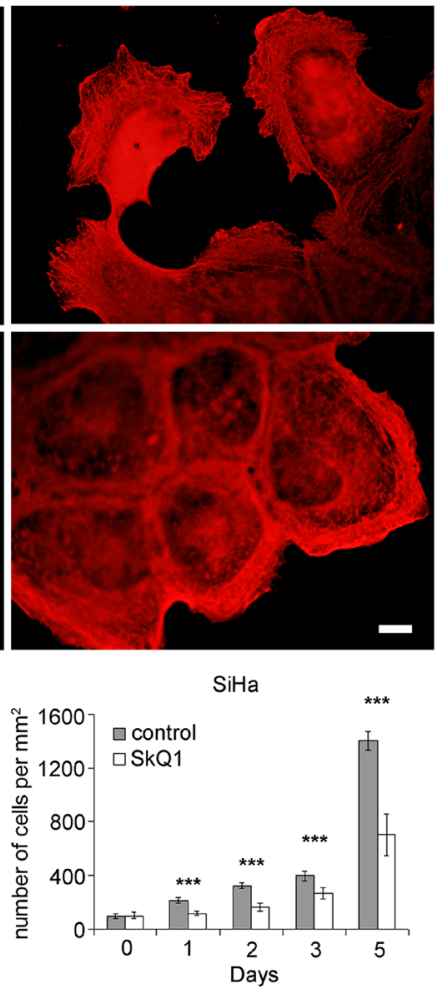

Figure 1: SkQ1 induced reorganization of cytoplasmic actins and inhibited proliferation of cervical cancer cells. A. $\beta$-cytoplasmic actin in the control or cells treated with SkQ1 (40 nM for 3 days). B. $\gamma$-cytoplasmic actin in the control or cells treated with SkQ1 (40 nM for 3 days); immunofluorescence microscopy, scale bar 10 $\mu \mathrm{m}$. C. Transwell migration assay performed on SiHa treated with SkQ1 $(40 \mathrm{nM})$, time point 16 hours. Statistically significant difference of data by Mann-Whitney test is marked $(* *)$ for $p<0.01$. D. Influence of SkQ1 $(40 \mathrm{nM})$ treatment on $\mathrm{SiHa}$ and $\mathrm{HaCaT}$ cells proliferation; phase contrast microscopy. Statistically significant difference of data by Student t-test is marked $(* * *)$ for $\mathrm{p}<0.001$. 
to SkQ1 molecule without antioxidant capacity, C12TPP (40 nM), didn't influence proliferation of SiHa and HaCaT cells (data not shown). These data stimulated the further studies on the role of mtROS in EMT.

\section{SkQ1 improved adhesion junctions}

Destabilization of intercellular contacts is one of the most important features of EMT. Actins are known to maintain stability of intercellular contacts. Both cytoplasmic actins were visualized at the apex of polarized epithelial cells in close proximity to intercellular contacts
$[28,31,32]$. Adhesion junctions (AJ) are connected to $\beta$-actin [28] so the $\beta$-actin rearrangement induced by SkQ1 could influence AJ organization in cervical carcinoma cells. E-cadherin is a major AJ protein which is abundant in normal epithelial tissues, but is often suppressed in epithelial tumors [34]. We compared changes in location and amount of E-cadherin in non-neoplastic HaCaT and cervical cancer cells in response to mtROS depletion.

Distribution and amount of E-cadherin in HaCaT cells was not affected by SkQ1 treatment (Figure 2A, 2C). E-cadherin amount in $\mathrm{SiHa}$ and $\mathrm{Ca}$-Ski cells was significantly lower than in $\mathrm{HaCaT}$ cells (Figure 2B).
A
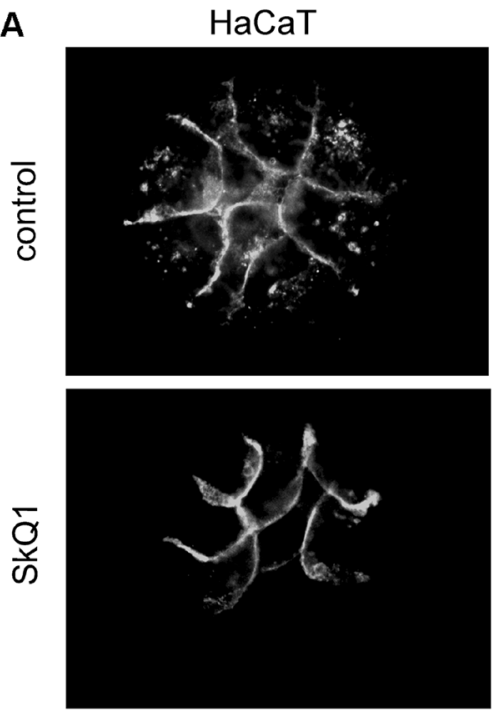

B
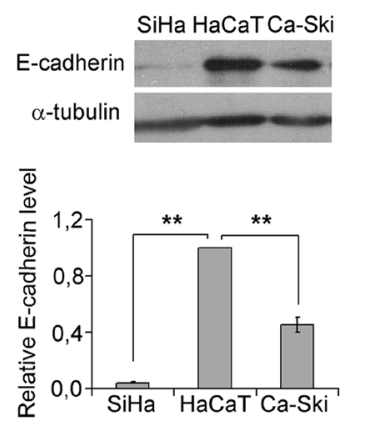

C
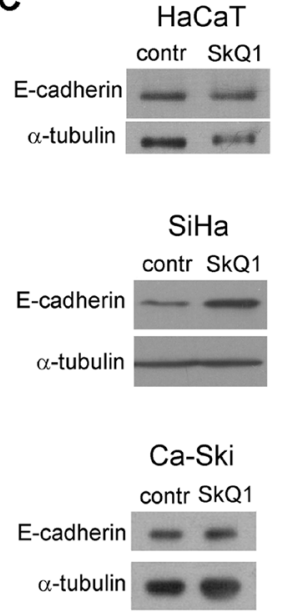

$\mathrm{SiHa}$
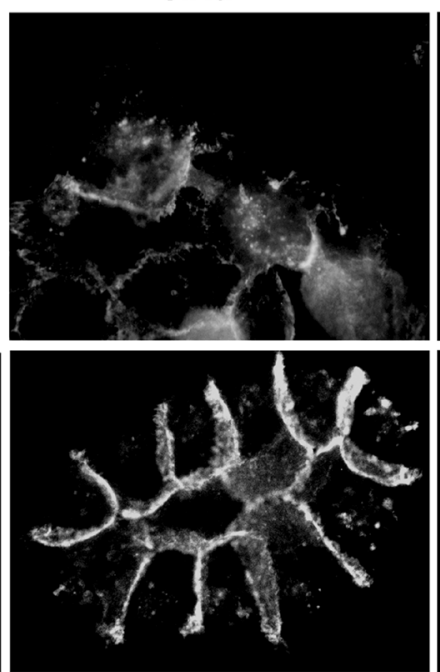

HaCaT

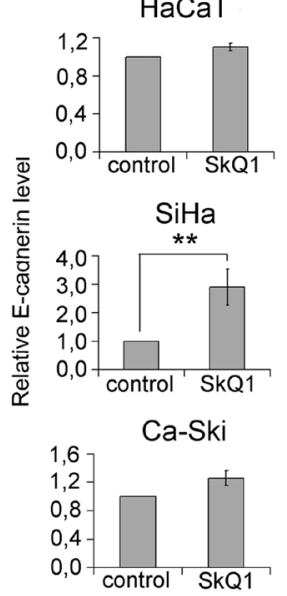

Ca-Ski

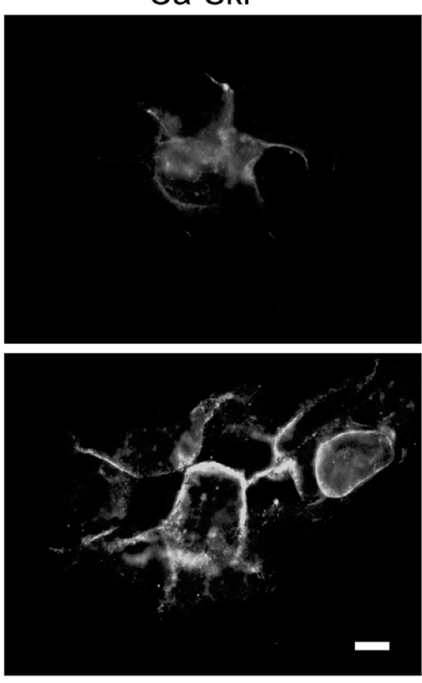

D

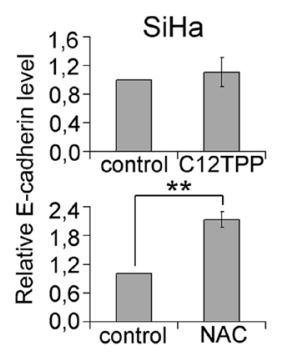

E

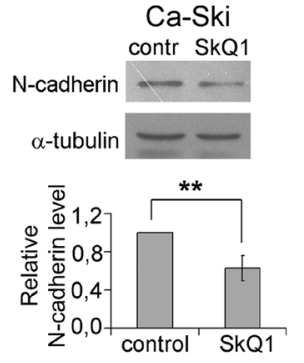

Figure 2: SkQ1 stimulated expression of E-cadherin and inhibited expression of $\mathrm{N}$-cadherin in cervical cancer cells. A. Distribution of E-cadherin in $\mathrm{HaCaT}$, SiHa, and Ca-Ski cells in control cells and cells treated with SkQ1 (40 nM, 7 days); immunofluorescence microscopy, scale bar $10 \mu \mathrm{m}$. B. E-cadherin expression in tumor SiHa and Ca-Ski cells compared to non-tumorigenic HaCaT cells; western blot analysis. C. E-cadherin expression in $\mathrm{HaCaT}$, SiHa, and Ca-Ski cells in response to SkQ1 (40 nM, 7 days); western blot analysis. D. E-cadherin expression in SiHa cells treated with C12TPP (40 nM, 7days) or NAC (5mM, 7 days); densitometric analysis of western blots. E. SkQ1 (40 nM, 7 days) decreased N-cadherin content in Ca-Ski cells; western blot analysis. Statistically significant difference of data by Mann-Whitney test is marked $(* *)$ for $\mathrm{p}<0.01$. 
E-cadherin was diffusely distributed in the cytoplasm with a higher concentration in the AJ zone of SiHa cells (Figure 2A). In Ca-Ski cells, E-cadherin was predominantly located in the AJ zone. SkQ1 stimulated E-cadherin expression in $\mathrm{SiHa}$ cells (Figure 2C) and induced a redistribution of E-cadherin to the $\mathrm{AJ}$ zone in $\mathrm{SiHa}$ and Ca-Ski cells (Figure 2A), where it was co-localized with $\beta$-actin (data not shown). C12TPP (40 nM, 7days), did not change E-cadherin expression and distribution in all three cultures (Figure 2D, for $\mathrm{SiHa}$ ). Treatment with the ROS scavenger NAC (5mM, 7 days) increased E-cadherin level in SiHa cells (Figure 2D). Metastatic Ca-Ski cells express both epithelial E-cadherin and mesenchymal N-cadherin, a marker of advanced EMT. We observed N-cadherin downregulation caused by SkQ1 in Ca-Ski cells (Figure $2 \mathrm{E})$. These data indicated that expression and distribution of E-cadherin as well as expression of $\mathrm{N}$-cadherin depend on mtROS in cervical carcinoma cells.

\section{SkQ1 downregulated transcription factor Snail}

Expression of E-cadherin can be regulated by different mechanisms [35]. Transcriptional repression is a fundamental mechanism for the dynamic silencing of E-cadherin gene. E-cadherin expression is downregulated by various transcription factors including Snail, Slug, Twist [36]. The amount of Snail in SiHa cells was significantly higher than in $\mathrm{HaCaT}$ while in Ca-Ski cells it was intermediate (Figure 3A). We observed a reduction of Snail in SiHa cells as a result of incubation with 40 nM SkQ1 (Figure 3B); effect was detected after one day of treatment and lasted until the 7 th day. Snail level in Ca-Ski cells did not change after SkQ1 treatment (data not shown). These data indicated that mtROS inhibited
E-cadherin expression via stimulation of Snail in SiHa cells while the other mechanisms were responsible for E-cadherin suppression in Ca-Ski cells.

\section{SkQ1 inhibited ERK1/2 activity and upregulated dual-specificity protein phosphatase DUSP6}

Transcription factor Snail could be activated by ERK1/2 pathway [37-39]. ERK-1 and ERK-2 (ERK1/2 hereafter) belong to mitogen-activated protein kinases (MAPK) that control proliferation, motility, adhesion, invasion, survival and play an important role in tumor progression. Thus, we investigated the possible involvement of MAPK signaling pathways in SkQ1induced changes in cervical cancer cells. We identified that SkQ1 treatment decreased ERK1/2 activation in $\mathrm{SiHa}$ and Ca-Ski cells (Figure 4A); the effect was detected after $45 \mathrm{~min}$ of incubation and lasted until the 7 th day. No significant changes in phosphorylation of another MAPK, p38 were observed after incubation with SkQ1 (data not shown).

Dual-specificity protein phosphatases (DUSPs) dephosporylate phosphothreonine and phosphotyrosine residues and inactivate MAPK. DUSP6 is a cytoplasmic enzyme which selectively dephosphorylates ERK1/2 [40]. We observed the increase in DUSP6 content in Ca-Ski cells as a result of SkQ1 treatment (Figure 4B), that could be responsible for ERK1/2 inhibition. DUSPs and MAPKs form feedback loops, each controlling activities of the other. Active ERK1/2 phosphorylate transcription factors ETS1/2 to downregulate activity of DUSP6 promoter and inhibit its expression [41]. Moreover ERK1/2 can phosphorylate DUSP6 and promote its subsequent degradation by the proteasome [42]. Thus ERK1/2
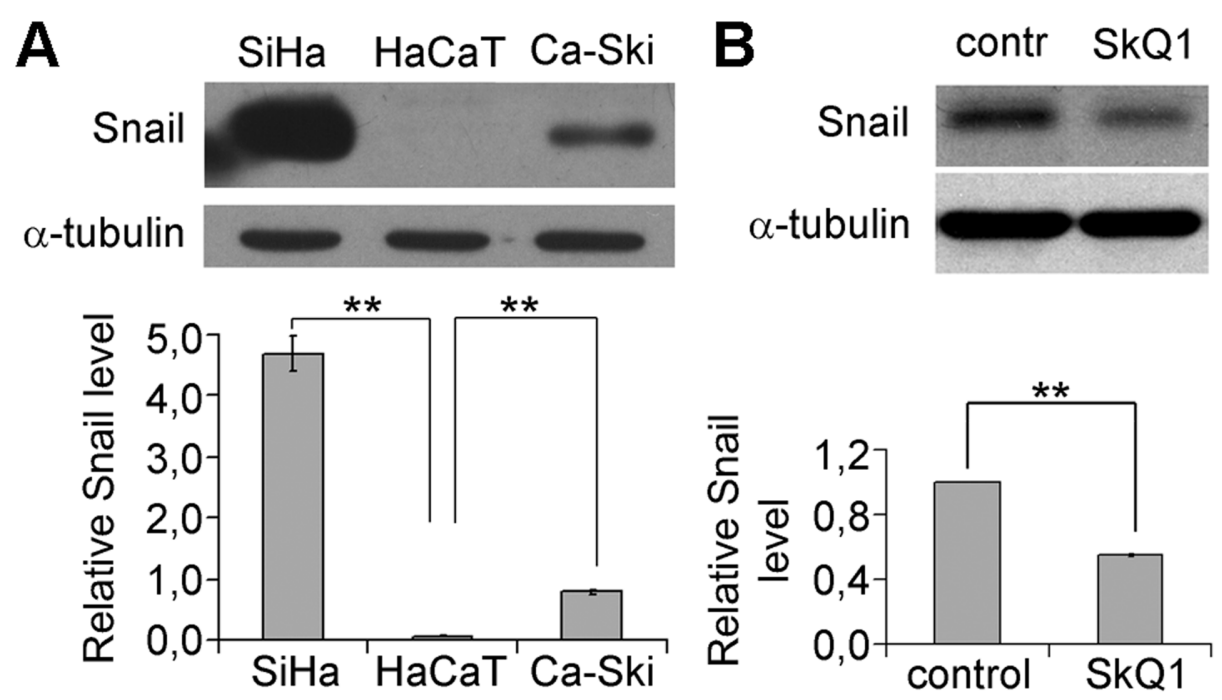

Figure 3: SkQ1 decreased Snail content in SiHa cells. A. Snail expression in HaCaT, SiHa and Ca-Ski cells; western blot analysis. B. Snail expression in SiHa cells in response to SkQ1 (40 nM, 1 day); western blot analysis. Statistically significant difference of data by Mann-Whitney test is marked $(* *)$ for $\mathrm{p}<0.01$. 
exert a positive feedback loop on their own activity by downregulation of DUSP6. Inhibition of ERK1/2 by mtROS depletion probably occurs, at least in part, due to interruption of these feedback mechanisms. The direct stimulation of DUSP6 activity by SkQ1 is also possible since this enzyme has cysteine in active site and could be inactivated by ROS.

\section{EGF-induced signaling leading to EMT progression was inhibited by SkQ1}

EGFR is known to activate EMT-inducing signaling pathways in cervical cancer [43]. EGFR signaling depends on $\mathrm{H}_{2} \mathrm{O}_{2}$ generation [44] and activation of ERK1/2 [45]. We observed simulation of EMT phenotype via EGF in SiHa and Ca-Ski cells and investigated the effect of SkQ1 on the process. Treatment with EGF induced accumulation of Snail in nucleus and significantly increased overall amount of Snail in SiHa cells (Figure 5A, 5B). Incubation with EGF stimulated ERK1/2 phosphorylation in SiHa and Ca-Ski cells (Figure 5C, 5D). Pre-incubation with SkQ1 downregulated Snail (Figure 5B) and ERK1/2 phosphorylation (Figure 5C) in SiHa cells, but did not affect ERK1/2 activation caused by EGF in Ca-Ski cells (Figure 6D). These data indicate that SkQ1 induced reverse of epithelial-to-mesenchymal transition in cervical cancer cells at least in part, due to inhibition of EGFR signaling.

\section{SkQ1 decreased accumulation of hydrogen peroxide in mitochondria}

SkQ1 is a mitochondria-targeted antioxidant $[16,17]$, but the direct measurements of SkQ1 effects on ROS accumulation in mitochondria are rarely performed. We measured intracellular ROS using dichlorodihydrofluorescein diacetate (DCFH-DA) and flow cytometry analysis. SkQ1 did not change significantly basic intracellular ROS, but it downregulated EGF-induced ROS increase in SiHa cells (Figure 6A). For measurements of ROS accumulation in mitochondria we used the lentiviral construct expressing mitochondria-targeted recombinant fluorescent protein HyPer-mito, a sensor for hydrogen peroxide in mitochondria [46]. We observed that hydrogen peroxide was reduced after SkQ1 treatment and increased after incubation with EGF in SiHa cells. SkQ1 suppressed the EGF-induced hydrogen peroxide accumulation in mitochondria of $\mathrm{SiHa}$ cells (Figure 6B, 6C). These data indicated that inhibition of ROS accumulation in mitochondria as a result of SkQ1 treatment could be responsible for its action on cervical cancer cells.

\section{DISCUSSION}

In agreement with earlier findings [16], we demonstrated that the mitochondria-targeted antioxidant SkQ1 (40 nM) inhibited proliferation of cervical carcinoma SiHa cells while proliferation of non-
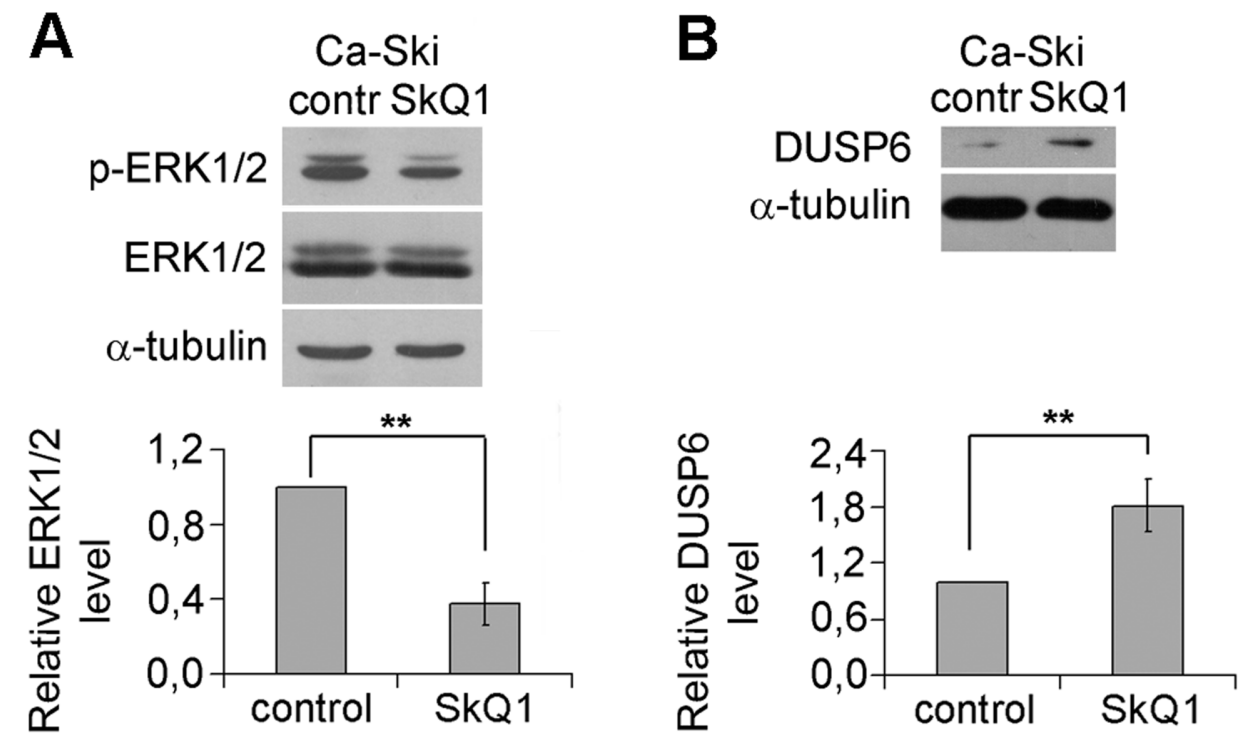

Figure 4: Inhibition of ERK1/2 phosphorylation (activation) and upregulation of DUSP6 expression by SkQ1 in CaSki cells. A. ERK1/2 phosphorylation altered as a result of SkQ1 (40 nM, 6 days) treatment; B. SkQ1 (40 nM, 6 days) influenced DUSP6 expression; western blot analysis. Statistically significant difference of data by Mann-Whitney test is marked $(* *)$ for $p<0.01$. 


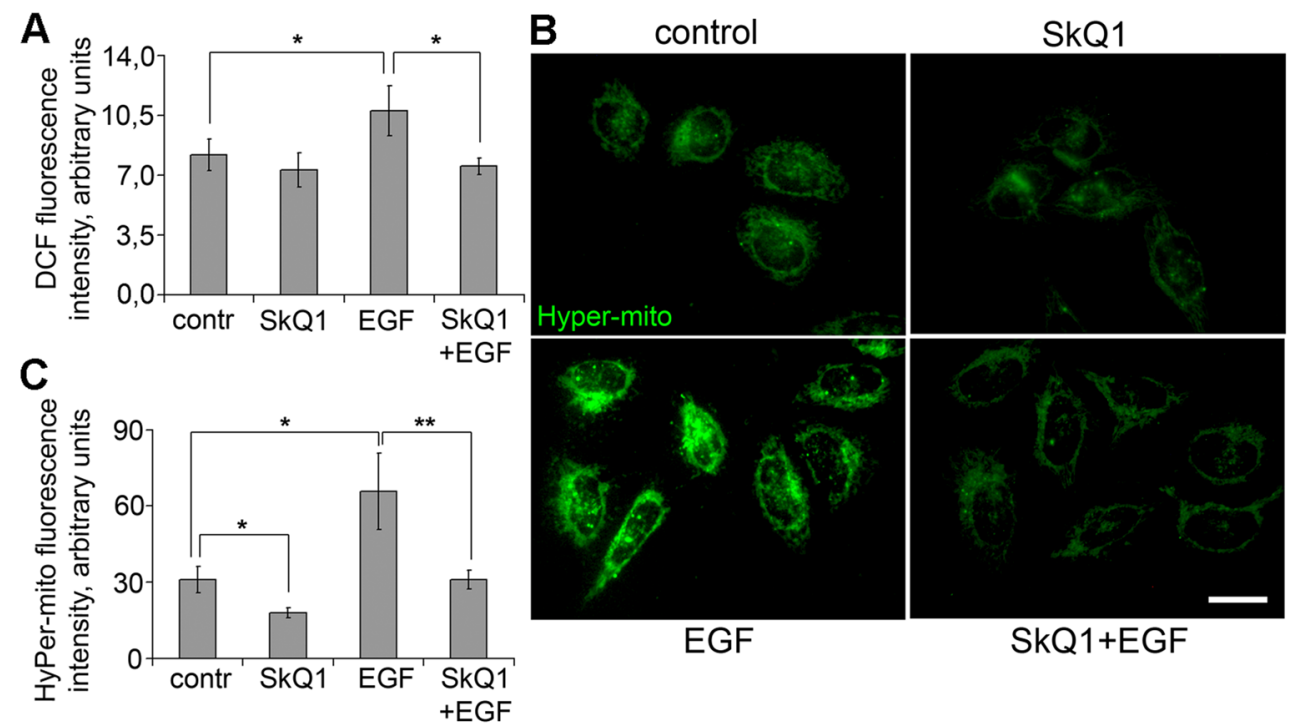

Figure 5: SkQ1 prevented accumulation of cytoplasmic and mitochondrial ROS induced by EGF in SiHa cells. A. Effect of SkQ1 (40 nM, 7 days) on accumulation of cytoplasmic ROS with or without and EGF (10 ng/ml, $10 \mathrm{~min}$ ); DCFH-DA assay, flow cytometry. B. and C. SkQ1 (20 nM, 1 day) influenced accumulation of mtROS with or without EGF (10 ng/ml, 2 hours); cells with mitoHyper sensor of $\mathrm{H}_{2} \mathrm{O}_{2}$, fluorescence microscopy, scale bar $20 \mu \mathrm{m}$. Statistically significant difference of data by Student's t-test is marked (*) for $\mathrm{p}<0.05$ and $(* *)$ for $\mathrm{p}<0.01$.
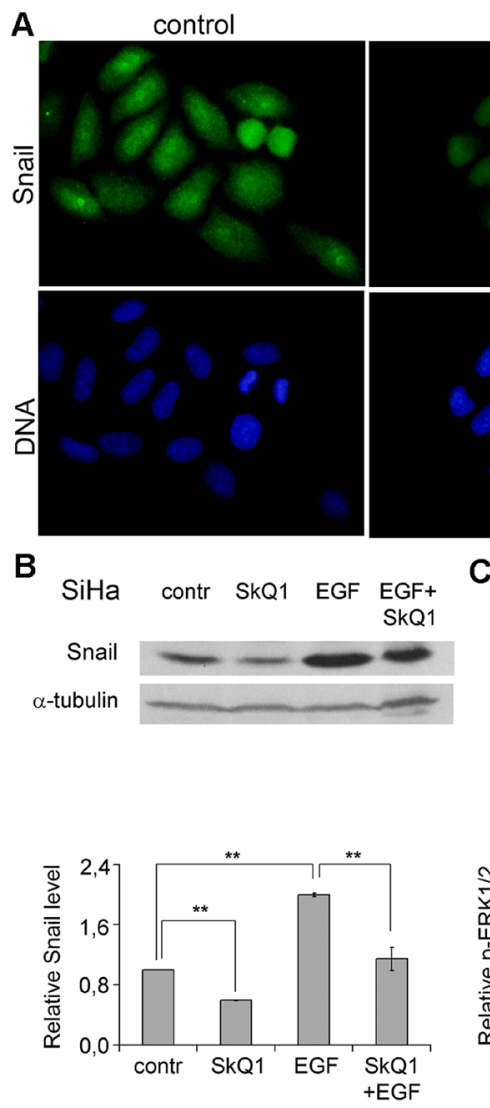

SkQ1
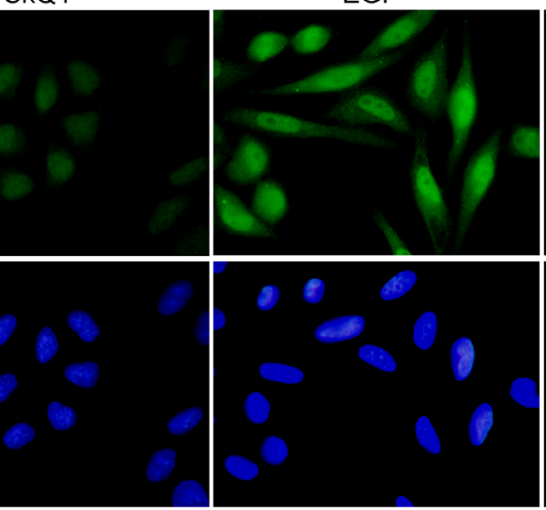

C
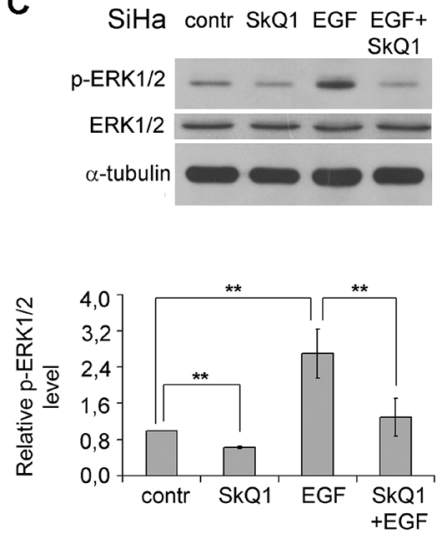
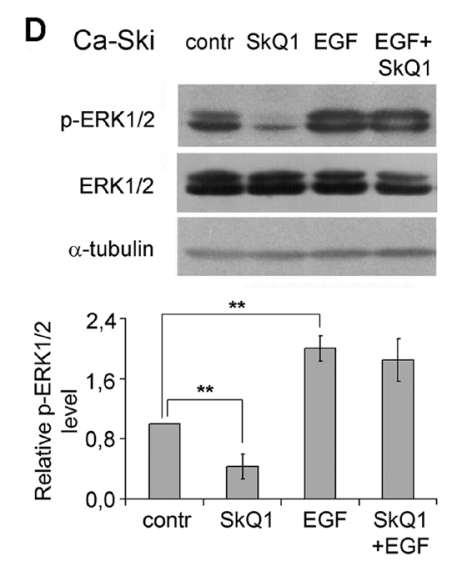

Figure 6: SkQ1 suppressed EGF induced signaling in cervical cancer cells. A. and B. SkQ1 (20 nM, 7 days) altered Snail expression induced by EGF (5 ng/ml, 3 days) in SiHa cells; immunofluorescence microscopy (A), scale bar 10 $\mu \mathrm{m}$; western blot analysis (B). C. SkQ1 (20 nM, 7 days) inhibited ERK1/2 activation induced by EGF ( $5 \mathrm{ng} / \mathrm{ml}, 3$ days) in SiHa cells; western blot analysis. D. Effect of SkQ1 (20 nM, 6 days) on ERK1/2 activation induced by EGF (5 ng/ml, 1 day) in Ca-Ski cells; western blot analysis. Statistically significant difference of data by Mann-Whitney test is marked $(* *)$ for $p<0.01$. 
tumorigenic keratinocytes $\mathrm{HaCaT}$ was not affected. Lipophilic cation C12TPP (which resembles SkQ1 but does not contain antioxidant plastoquinolyl residue) did not influence proliferation of SiHa cells. Compared with SkQ1, non-targeted antioxidant NAC (5mM) inhibited proliferation of $\mathrm{SiHa}$ cells at a significantly higher concentration, indicating that scavenging of mtROS was critical for the antiproliferative action of SkQ1. Effective inhibition of the ROS accumulation in mitochondria of SiHa cells by SkQ1 was shown using a mitochondriatargeted hydrogen peroxide sensor HyPer-mito.

The antiproliferative action of SkQ1 could be mediated by reorganization of $\beta$-actin cytoskeleton and inhibition of MAPK signaling in cervical cancer cells. In addition to architectonics, intracellular transport and motility of the cells, actin cytoskeleton is important for proliferation and intracellular signaling. Decreased $\beta$-actin coupled with abundant $\gamma$-actin was detected in cervical and breast tumors compared to corresponding normal tissues [26, 32]. Previously [47] we showed that $\beta$-actin acts as a tumor suppressor, inhibiting cell proliferation and invasion in vitro and tumor growth in vivo. ERK1/2 activation is linked to $\beta$-actin decrease and $\gamma$-actin upregulation in carcinoma cells. Contraction and adhesion are linked to $\beta$-actin, whereas $\gamma$-actin is predominantly organized in a cortical network which is necessary for the maintaining cell architecture and motility of normal fibroblasts and epithelial cells [29]. The loss of actin bundles correlates with an increase of migratory activity and metastatic potential of tumor cells. We conclude that a reorganization of $\beta$-actin into circular bundles as a result of SkQ1 treatment contributed to suppression of migration and proliferation in cervical cancer cells. The precise mechanisms by which mtROS regulate $\beta$-actin cytoskeleton reorganization require further investigation.

Cytoplasmic $\beta$-actin interacts with E-cadherin, principle AJ protein [28]. Rearrangement of $\beta$-actin and recruitment of $\beta$-actin bundles to AJ (probably due to E-cadherin upregulation) improved $\mathrm{AJ}$ in cervical carcinoma cells treated with SkQ1. Decreased expression of E-cadherin is thought to be the prototypical marker of EMT [48]. The loss of E-cadherin is associated with a tumor progression in various epithelial cancers while recovery of E-cadherin adhesion complex suppresses invasiveness of different tumor cells [48, 49].

SkQ1 stimulated E-cadherin expression in $\mathrm{SiHa}$ cells and induced a redistribution of E-cadherin to the $\mathrm{AJ}$ zone in the both $\mathrm{SiHa}$ and $\mathrm{Ca}-\mathrm{Ski}$ cells. Increased expression of E-cadherin in $\mathrm{SiHa}$ was accompanied by downregulation of Snail. Snail is a transcriptional repressor of E-cadherin which induces tumor invasion during cancer progression and also triggers EMT during the embryonic development of diverse species from Drosophila to mammals. No deviations occurred during the embryogenesis in mice receiving SkQ1 [M.V. Skulachev, personal communication].
The expression of Snail is stimulated by ERK1/2 [37-39] and positive feedback regulation of ERK2 by Snail was observed in breast cancer cells MCF-7 [51]. SkQ1 decreased ERK1/2 activation in cervical cancer cells suggesting that inhibition of Snail expression by SkQ1 could be mediated via ERK1/2 inhibition. Snail acts downstream of EMT-inducing signaling pathways which can be activated by different growth factors including EGF. Epidermal growth factor receptor (EGFR) is overexpressed in $70 \%$ to $90 \%$ of analyzed cervical cancer cases [52]. Immunofluorescent study of surgical specimens indicated that cervical carcinoma progression was accompanied by EGFR overexpression and decreased E-cadherin content that correlated with Snail upregulation [43]. To study the role of EGFR signaling in cervical cancer cells we stimulated EMT progression with exogenous EGF. It was shown that activation of ERK1/2 and Snail by EGF in SiHa cells was prevented by SkQ1 suggesting that EGFR signaling critically depends on mtROS.

EGF increased accumulation of mitochondrial ROS as well as cytoplasmic ROS and SkQ1 prevented the both effects indicating that mtROS could be the primary target of EGFR signaling. One of the possible mechanisms of EGFR-dependent mtROS production is related to activation of p66shc protein that can generate ROS in mitochondria [53]. EGFR pathway is controlled by redox-dependent mechanisms at various levels. It was shown that p66shc-dependent mtROS stimulated EGFR and platelet-derived growth factor receptor signaling via oxidation and inhibition of protein tyrosine phosphatases [54]. SkQ1 inhibited mtROS in the cells overexpressing p66shc [55] so downregulation of EGFR signaling in cervical cancer cells was probably mediated by inhibition of p66shc-dependent mtROS production.

Oxidative inhibition of protein tyrosine phosphatases is the most general mechanism regulating signal transduction. MAPK phosphatases (MKPs) are dual-specificity phosphatases (DUSPs) that are highly specific for the MAPKs and can be regulated at the level of gene expression. This subclass of protein phosphatases is capable of direct binding to MAPKs, resulting in dephosphorylation of phosphothreonine and phosphotyrosine residues and inactivation of MAPKs. DUSP6 (MKP-3) is a cytoplasmic enzyme which selectively dephosphorylates and inactivates ERK1/2 [56]. In ovarian cancer cells oxidative stress resulted in DUSP6 ubiquitination and proteasomal degradation followed by ERK1/2 activation, tumor progression and development of chemoresistance in vitro and in vivo [57]. ROS scavenging by an antioxidant N-acetyl-L-cysteine increased DUSP6 expression as well as dephosphorylation of ERK1/2, and inhibited ovarian cancer cells proliferation [57]. Increased ROS production also resulted in the antioxidant response element (ARE)/Nrf2-dependent upregulation of the transcription factor ETS1 [58]. Notably ERK1/2 can 
phosphorylate transcription factors ETS1/2 and inhibit DUSP6 expression [41]. At the same time, ERK1/2 directly phosphorylate serines 159 and 197 of DUSP6 and stimulated its proteasomal degradation [42]. These data demonstrated that there are several pathways for ROS-dependent dowregulation of DUSP6. Since SkQ1 stimulated DUSP6 and prevented ERK1/2 activation in $\mathrm{Ca}$-Ski cells the key role of mtROS in these pathways could be suggested.

We demonstrated that scavenging of mtROS with SkQ1 resulted in actin cytoskeleton reorganization and ERK1/2 inactivation in both $\mathrm{SiHa}$ and $\mathrm{Ca}$-Ski cells, but downregulation of Snail followed by increase in E-cadherin expression was detected in SiHa cells only. $\mathrm{SiHa}$ and $\mathrm{Ca}-\mathrm{Ski}$ cells display two different stages of cancer progression as they were derived from primary tumor and cervical carcinoma metastasis, respectively. ERK1/2-dependent Snail activation at the early stages of tumorigenesis leads to rapid and effective repression of E-cadherin that promotes EMT to initiate invasion. This pathway critically depends on increased mtROS production as we saw in SiHa. Maintenance of the motile phenotype in invading tumor cells depends on weaker but more widely expressed repressors Slug, E47, and SIP1 while Twist1 plays a key role in distant metastasis [59]. In Ca-Ski cells derived from metastasis E-cadherin is partially replaced by mesenchymal $\mathrm{N}$-cadherin that is known to form the weaker intercellular adhesions [2]. Moreover, N-cadherin contributed to sustained activation of the MAPK-ERK pathway, leading to transcription of matrix metalloprotease MMP-9 gene and cellular invasion [60]. Forced expression of N-cadherin in welldifferentiated breast cells increases invasiveness of cells even in presence of high E-cadherin expression [61]. SkQ1 decreased expression of N-cadherin in Ca-Ski cells indicating that mtROS contributed to EMT promotion in the cells derived from metastasis of cervical carcinoma. In Ca-Ski cells EGF-induced ERK1/2 activation was not affected by SkQ1 in contrast to SiHa cells. This difference occurs at least in part because EGFR expression in $\mathrm{Ca}$-Ski is about 6 times higher than in SiHa cells [62].

Tumor-initiating cells (TICs) from carcinomas of several different types carry distinct mesenchymal features, that suggests they have passed through the EMT which helped them to acquire properties of stem cells [63]. TICs are important targets for cancer therapy owing to their higher tumor-initiating ability and elevated resistance to chemotherapy [64]. Upregulation of E-cadherin expression diminishes the number of TICs and decelerates tumor growth in human A549 lung adenocarcinoma cells [65]. EMT reversal in mesenchymal derivatives of human mammary epithelial cells stimulated them to enter epithelial non-stem-like state that made chemotherapy more cytotoxic to them [66].

In conclusion, we showed that scavenging of mtROS by SkQ1 initiated reversal of EMT in cervical carcinoma cells as revealed by an upregulation of epithelial markers and a downregulation of mesenchymal markers. These findings suggest that mitochondria-targeted antioxidants could be considered as potential partner drugs in a combinational therapy of cervical cancers.

\section{MATERIALS AND METHODS}

\section{Cell culture and chemicals}

$\mathrm{SiHa}$ and $\mathrm{Ca}$-Ski cells were obtained from the American type culture collection (ATCC): SiHa cell line (ATCC \#HTB-35) was derived from a surgical material of cervical carcinoma; cells contain one or two copies of the human papilloma virus 16 type (HPV 16) DNA integrated in the chromosome 13. Ca-Ski cell line (ATCC \#CRL1550) was derived from a surgical specimen of cervical carcinoma metastasis into the intestinal mesentery; cells contain integrated DNA of HPV 16 (about 600 copies per cell) and fragments of HPV 18 DNA. HaCaT are spontaneously immortalized in vitro keratinocytes from a surgical specimen of histologically normal human skin [30].

Cell lines were maintained in Dulbecco's modified Eagle media (DMEM) with $5 \%$ fetal bovine serum (HyClone), $5 \mathrm{MM}$ glutamic acid (PanEco) at $37^{\circ} \mathrm{C}$ in the atmosphere of air containing $5 \% \mathrm{CO}$.

$$
\text { SkQ1 (10-(6'-plastoquinonyl) }
$$
decyltriphenylphosphonium) is a conjugate of $\mathrm{TPP}^{+}$with the plant electron carrier plastoquinone [17]. C12TPP is a structurally related to SkQ1 molecule lacking the plastoquinol moiety. Both SkQ1 and C12TPP in their cationic forms can penetrate the planar bilayer phospholipid membrane and accumulate in isolated mitochondria or in mitochondria in human cells in culture. Optimal according to our observations concentrations $20-40 \mathrm{nM}$ were used for SkQ1 and C12TPP. For EMT stimulation via human epidermal growth factor (EGF, Cell Signaling) cells were maintained in DMEM with $1 \%$ fetal bovine serum and $5 \mathrm{MM}$ glutamic acid. For short-term experiments (5 min - 2 hours) we used $10 \mathrm{ng} / \mathrm{ml}$ of EGF, for long-term experiments we used $5 \mathrm{ng} / \mathrm{ml}$ of EGF. NAC (Sigma) was used in concentration $5 \mathrm{mM}$.

\section{Immunofluorescence microscopy}

The cells were cultivated on the glass cover slips washed with DMEM containing $20 \mathrm{mM}$ 4-(2-hydroxyethyl)-1-piperazineethanesulfonic acid (HEPES) at $37^{\circ} \mathrm{C}$. The cells were fixed for 15 min with $1 \%$ paraformaldehyde on a serum-free DMEM (with 20 $\mathrm{mM}$ HEPES), and were extracted using cold methanol for $5 \mathrm{~min}$ at $-20^{\circ} \mathrm{C}$ for subsequent antibody staining. The following antibodies were used: mouse monoclonal antibodies against cytoplasmic $\beta$-actin (4C2 clone), cytoplasmic $\gamma$-actin (2A3 clone; Dugina et al., 2009), E-cadherin (BD Transduction Laboratories), rat antibodies 
against Snail (Cell Signaling). The secondary antibodies were goat fluorescein- and rhodamine-conjugated antibodies against mouse immunoglobulins $\operatorname{IgG} 2 \mathrm{a}, \mathrm{IgG} 2 \mathrm{~b}$, and IgG1 (Southern Biotechnology). Nuclear staining was performed using DAPI (Sigma). Immunofluorescence was observed using Axioplan microscope with $40 \times / 0.75$ and 100×/1.3 Plan-Neofluar lenses (Carl Zeiss).

\section{Western blot analysis}

Cells were extracted with cold sample buffer (62.5 $\mathrm{mM}$ Tris- $\mathrm{HCl}, \mathrm{pH} 6.8,2 \%$ sodium dodecyl sulfate (SDS), $10 \%$ glycerin, $50 \mathrm{mM}$ dithiothreitol, $0.01 \%$ bromophenol blue). Lysates were separated in 10\% SDS polyacrylamide gel and transferred onto polyvinylidene fluoride membrane (Amersham GE Healthcare). After blocking the nonspecific binding using bovine serum albumin, the membranes were incubated with specific antibodies against $\beta$-actin, $\gamma$-actin, E-cadherin, Snail; rabbit antibodies against ERK1/2(p42/44) and phosphorylated ERK1/2 (p-p42/44) (Cell Signaling), p38 and p-p38 (Cell Signaling), DUSP6 (Cell Signaling). We used $\alpha$-tubulin as a loading control. The membranes were incubated with secondary antibodies bound with horseradish peroxidase (Amersham GE Healthcare). The membranes were developed using the chemiluminescence technique with ECL reagents (Amersham GE Healthcare) according to producer's protocol. The resulting films were scanned and analyzed densitometrically with ImageJ $1,37 \mathrm{C}$ software (NIH, http://rsb.info.nih.gov/ij/).

\section{Detection of reactive oxygen species}

For the intracellular ROS measurement, we incubated $\mathrm{SiHa}$ cells with the fluorescent dye $2^{\prime}, 7^{\prime}$-di chlorodihydrofluorescein diacetate, DCFH-DA («Invitrogen», $1.8 \mu \mathrm{M}$ ) for $10 \mathrm{~min}$ on a serum-free DMEM medium at $37^{\circ} \mathrm{C}$ in the dark. After the oxidation by ROS dichlorodihydrofluorescein transforms to the highly fluorescent dichlorofluorescin (DCF). Then cells were detached with the trypsin-EDTA solution and ROS accumulation was measured by flow cytometry with Beckman Coulter Cytomics FC500 at the $525 \mathrm{~nm}$ wavelength, with excitation at the $488 \mathrm{~nm}$ wavelength.

For measurements of ROS accumulation in mitochondria we used the lentiviral construct expressing mitochondria-targeted recombinant fluorescent protein HyPer-mito, a sensor for hydrogen peroxide in mitochondria [46] introduced in SiHa cells. Cells were cultivated on the glass cover slips and washed with DMEM containing $20 \mathrm{mM}$ HEPES at $37^{\circ} \mathrm{C}$. Cells were fixed for 15 min with $1 \%$ paraformaldehyde on a serum-free DMEM (with $20 \mathrm{mM}$ HEPES). HyPer-mito fluorescence was observed using Axioplan microscope with $100 \times / 1.3$ Plan-Neofluar lenses (Carl Zeiss) and was analyzed with Image J $1,37 \mathrm{C}$ software.

\section{Transwell migration assay}

The assay was performed using transwell chambers with 8 - $\mu \mathrm{m}$ pore-size membranes (Corning Life Sciences) according to manufacturer protocol with $10^{4} \mathrm{SiHa}$ cells from 0,1 to $5 \%$ of FBS. The migration activity was quantified by the number of migrated cells (time point 16 hours) from 10 fields per chamber in 3 independent experiments.

\section{Statistical analysis}

Results are presented indicating mean \pm standard error of the mean of at least three independent experiments. Intergroup differences were analyzed by the Mann-Whitney U test or Student's t-test when applicable. Values of $\mathrm{p}<0.001(* * *), \mathrm{p}<0.01(* *)$, and $\mathrm{p}<0.05(*)$ were considered as statistically significant.

\section{Abbreviations}

epithelial-to-mesenchymal transition (EMT), reactive oxygen species (ROS), mitochondrial reactive oxygen species (mtROS), N-acetyl-L-cysteine (NAC), american type culture collection (ATCC), human papillomavirus (HPV), Dulbecco's modified Eagle media (DMEM), epidermal growth factor (EGF), sodium dodecyl sulfate (SDS), 4-(2-hydroxyethyl)1-piperazineethanesulfonic acid (HEPES), adhesion junctions (AJ), mitogen-activated protein kinases (MAPK), extracellular-signal-regulated kinases 1 and 2 (ERK1/2), dual-specificity protein phosphatases (DUSPs), epidermal growth factor receptor (EGFR), tumor necrosis factor (TNF), mesenchymal-to-epithelial transition (MET), tumor-initiating cells (TICs)

\section{ACKNOWLEDGMENTS}

We would like to acknowledge Dr. Yevgeny Galimov for provision of $\mathrm{SiHa}$ cells with the lentiviral construct expressing HyPer-mito and Nikolay Zak for a critical reading of the manuscript. This work was supported by research grant from the Russian Science Foundation to Vladimir Skulachev (project No. 14-2400107).

\section{CONFLICTS OF INTEREST}

The authors declare no conflicts of interest.

\section{REFERENCES}

1. Yilmaz M, Christofori G. EMT, the cytoskeleton, and cancer cell invasion. Cancer Metastasis Rev. 2009; 28:1533. doi: 10.1007/s10555-008-9169-0. 
2. Ye X, Weinberg RA. Epithelial-Mesenchymal Plasticity: A Central Regulator of Cancer Progression. Trends Cell Biol. 2015; 25:675-86. doi: 10.1016/j.tcb.2015.07.012.

3. Thiery JP. Epithelial-mesenchymal transitions in tumour progression. Nat Rev Cancer. 2002; 2:442-54. doi: 10.1038/ nrc822.

4. Moustakas A, Heldin C-H. Signaling networks guiding epithelial-mesenchymal transitions during embryogenesis and cancer progression. Cancer Sci. 2007; 98:1512-20. doi: 10.1111/j.1349-7006.2007.00550.x.

5. Acloque H, Adams MS, Fishwick K, Bronner-Fraser M, Nieto MA. Epithelial-mesenchymal transitions: The importance of changing cell state in development and disease. J Clin Invest. 2009; 119:1438-49. doi: 10.1172/ JCI38019.

6. Liu M, Casimiro MC, Wang C, Shirley LA, Jiao X, Katiyar S, Ju X, Li Z, Yu Z, Zhou J, Johnson M, Fortina P, Hyslop T, et al. p21CIP1 attenuates Ras- and c-Myc-dependent breast tumor epithelial mesenchymal transition and cancer stem cell-like gene expression in vivo. Proc Natl Acad Sci U S A. 2009; 106:19035-9. doi: 10.1073/pnas.0910009106.

7. Xie G, Yao Q, Liu Y, Du S, Liu A, Guo Z, Sun A, Ruan J, Chen L, Ye C, Yuan Y. IL-6-induced epithelialmesenchymal transition promotes the generation of breast cancer stem-like cells analogous to mammosphere cultures. Int J Oncol. 2012; 40:1171-9. doi: 10.3892/ijo.2011.1275.

8. Leung CT, Brugge JS. Outgrowth of single oncogeneexpressing cells from suppressive epithelial environments. Nature. 2012; 482:410-3. doi: 10.1038/nature10826.

9. Fruehauf JP, Meyskens FL. Reactive oxygen species: a breath of life or death? Clin Cancer Res. 2007; 13:789-94. doi: 10.1158/1078-0432.CCR-06-2082.

10. Glasauer A, Chandel NS. Targeting antioxidants for cancer therapy. Biochem Pharmacol. 2014; 92:90-101. doi: 10.1016/j.bcp.2014.07.017.

11. Piskounova E, Agathocleous M, Murphy MM, Hu Z, Huddlestun SE, Zhao Z, Leitch AM, Johnson TM, DeBerardinis RJ, Morrison SJ. Oxidative stress inhibits distant metastasis by human melanoma cells. Nature. 2015; 527:186-91. doi: 10.1038/nature15726.

12. Le Gal K, Ibrahim MX, Wiel C, Sayin VI, Akula MK, Karlsson C, Dalin MG, Akyürek LM, Lindahl P, Nilsson J, Bergo MO. Antioxidants can increase melanoma metastasis in mice. Sci Transl Med. 2015; 7:308re8. doi: 10.1126/ scitranslmed.aad3740.

13. Sabharwal S, Schumacker P. Mitochondrial ROS in cancer: initiators, amplifiers or an Achilles' heel? Nat Rev Cancer. 2014; 14:709-21. doi: 10.1038/nrc3803.

14. Loo SY, Hirpara JL, Pandey V, Tan TZ, Lobie PE, Thiery JP, Goh BC, Pervaiz S, Ronique M-V, Ment C, Kumar AP. Manganese Superoxide Dismutase Expression Regulates the Switch Between an Epithelial and a MesenchymalLike Phenotype in Breast Carcinoma. doi: 10.1089/ ars.2015.6524.
15. Bernal SD, Lampidis TJ, Summerhayes IC, Chen LB. Rhodamine-123 selectively reduces clonal growth of carcinoma cells in vitro. Science. 1982; 218:1117-9.

16. Agapova LS, Chernyak BV, Domnina LV, Dugina VB, Efimenko AY, Fetisova EK, Ivanova OY, Kalinina NI, Khromova NV, Kopnin BP, Kopnin PB, Korotetskaya MV, Lichinitser MR, et al. Mitochondria-targeted plastoquinone derivatives as tools to interrupt execution of the aging program. 3. Inhibitory effect of SkQ1 on tumor development from p53-deficient cells. Biochem. 2008; 73:1300-16.

17. Antonenko Y, Avetisyan A, Bakeeva L, Chernyak B, Chertkov V, Domnina L, Ivanova O, Izyumov D, Khailova L, Klishin S, Korshunova G, Lyamzaev K, Muntyan M, et al. Mitochondria-targeted plastoquinone derivatives as tools to interrupt execution of the aging program. 1. Cationic plastoquinone derivatives: synthesis and in vitro studies. Biochem. 2008; 73:1273-87.

18. Skulachev M V, Antonenko YN, Anisimov VN, Chernyak B V, Cherepanov DA, Chistyakov VA, Egorov M V, Kolosova NG, Korshunova GA, Lyamzaev KG, Plotnikov EY, Roginsky VA, Savchenko AY, et al. Mitochondrialtargeted plastoquinone derivatives. Effect on senescence and acute age-related pathologies. Curr Drug Targets. 2011; 12:800-26.

19. Starenki D, Park J-I. Mitochondria-targeted nitroxide, Mito-CP, suppresses medullary thyroid carcinoma cell survival in vitro and in vivo. J Clin Endocrinol Metab. 2013; 98:1529-40. doi: 10.1210/jc.2012-3671.

20. Nazarewicz RR, Dikalova A, Bikineyeva A, Ivanov S, Kirilyuk IA, Grigor'ev IA, Dikalov SI. Does scavenging of mitochondrial superoxide attenuate cancer prosurvival signaling pathways? Antioxid Redox Signal. 2013; 19:3449. doi: 10.1089/ars.2013.5185.

21. Cheng G, Zielonka J, McAllister DM, Mackinnon AC, Joseph J, Dwinell MB, Kalyanaraman B. Mitochondriatargeted vitamin $\mathrm{E}$ analogs inhibit breast cancer cell energy metabolism and promote cell death. BMC Cancer. 2013; 13:285. doi: 10.1186/1471-2407-13-285.

22. Cheng G, Zielonka J, McAllister D, Hardy M, Ouari O, Joseph J, Dwinell MB, Kalyanaraman B. Antiproliferative effects of mitochondria-targeted cationic antioxidants and analogs: Role of mitochondrial bioenergetics and energysensing mechanism. Cancer Lett. 2015; 365:96-106. doi: 10.1016/j.canlet.2015.05.016.

23. Kelso GF, Porteous CM, Coulter C V, Hughes G, Porteous WK, Ledgerwood EC, Smith RA, Murphy MP. Selective targeting of a redox-active ubiquinone to mitochondria within cells: antioxidant and antiapoptotic properties. J Biol Chem. 2001; 276:4588-96. doi: 10.1074/jbc.M009093200.

24. Rao VA, Klein SR, Bonar SJ, Zielonka J, Mizuno N, Dickey JS, Keller PW, Joseph J, Kalyanaraman B, Shacter E. The antioxidant transcription factor $\mathrm{Nrf} 2$ negatively regulates autophagy and growth arrest induced by the anticancer 
redox agent mitoquinone. J Biol Chem. 2010; 285:3444759. doi: 10.1074/jbc.M110.133579.

25. Vandekerckhove J, Weber K. At least six different actins are expressed in a higher mammal: an analysis based on the amino acid sequence of the amino-terminal tryptic peptide. J Mol Biol. 1978; 126:783-802. doi: 10.1016/0022-2836(78)90020-7.

26. Rubenstein PA. The functional importance of multiple actin isoforms. Bioessays. 1990; 12:309-15. doi: 10.1002/ bies.950120702.

27. Shagieva GS, Domnina L V, Chipysheva TA, Ermilova VD, Chaponnier C, Dugina VB. Actin isoforms and reorganization of adhesion junctions in epithelialto-mesenchymal transition of cervical carcinoma cells. Biochem. 2012; 77:1266-76. doi: 10.1134/ S0006297912110053.

28. Baranwal S, Naydenov NG, Harris G, Dugina V, Morgan $\mathrm{KG}$, Chaponnier C, Ivanov AI. Nonredundant roles of cytoplasmic $\beta$ - and $\gamma$-actin isoforms in regulation of epithelial apical junctions. Mol Biol Cell. 2012; 23:354253. doi: 10.1091/mbc.E12-02-0162.

29. Dugina V, Zwaenepoel I, Gabbiani G, Clément S, Chaponnier C. Beta and gamma-cytoplasmic actins display distinct distribution and functional diversity. J Cell Sci. 2009; 122:2980-8. doi: 10.1242/jcs.041970.

30. Boukamp P, Petrussevska RT, Breitkreutz D, Hornung J, Markham A, Fusenig NE. Normal keratinization in a spontaneously immortalized aneuploid human keratinocyte cell line. J Cell Biol. 1988; 106:761-71.

31. Lehman TA, Modali R, Boukamp P, Stanek J, Bennett WP, Welsh JA, Metcalf RA, Stampfer MR, Fusenig N, Rogan EM. p53 mutations in human immortalized epithelial cell lines. Carcinogenesis. 1993; 14:833-9.

32. Yao X, Chaponnier C, Gabbiani G, Forte JG. Polarized distribution of actin isoforms in gastric parietal cells. Mol Biol Cell. 1995; 6:541-57.

33. Dugina VB, Chipysheva TA, Ermilova VD, Gabbiani D, Chaponnier C, Vasil'ev IM. Distribution of actin isoforms in normal, dysplastic, and tumorous human breast cells. Arkh Patol. 2008; 70:28-31.

34. Wheelock MJ, Soler AP, Knudsen KA. Cadherin junctions in mammary tumors. J Mammary Gland Biol Neoplasia. $2001 ; 6: 275-85$

35. Peinado H, Olmeda D, Cano A. Snail, Zeb and bHLH factors in tumour progression: an alliance against the epithelial phenotype? Nat Rev Cancer. 2007; 7:415-28. doi: 10.1038/nrc2131.

36. Bolós V, Peinado H, Pérez-Moreno MA, Fraga MF, Esteller M, Cano A. The transcription factor Slug represses E-cadherin expression and induces epithelial to mesenchymal transitions: a comparison with Snail and E47 repressors. J Cell Sci. 2003; 116:499-511.

37. Montserrat N, Mozos A, Llobet D, Dolcet X, Pons C, De Herreros AG, Matias-Guiu X, Prat J. Epithelial to mesenchymal transition in early stage endometrioid endometrial carcinoma. Hum Pathol. 2012; 43:632-43. doi: 10.1016/j.humpath.2011.06.021.

38. Nagarajan D, Melo T, Deng Z, Almeida C, Zhao W. ERK/GSK3 $\beta /$ Snail signaling mediates radiationinduced alveolar epithelial-to-mesenchymal transition. Free Radic Biol Med. 2012; 52:983-92. doi: 10.1016/j. freeradbiomed.2011.11.024.

39. Vergara D, Valente CM, Tinelli A, Siciliano C, Lorusso V, Acierno R, Giovinazzo G, Santino A, Storelli C, Maffia M. Resveratrol inhibits the epidermal growth factor-induced epithelial mesenchymal transition in MCF-7 cells. Cancer Lett. 2011; 310:1-8. doi: 10.1016/j.canlet.2011.04.009.

40. Keyse SM. Dual-specificity MAP kinase phosphatases (MKPs) and cancer. Cancer Metastasis Rev. 2008; 27:25361. doi: 10.1007/s10555-008-9123-1.

41. Plotnik JP, Budka JA, Ferris MW, Hollenhorst PC. ETS1 is a genome-wide effector of RAS/ERK signaling in epithelial cells. Nucleic Acids Res. 2014; 42:11928-40. doi: 10.1093/ nar/gku929.

42. Marchetti S, Gimond C, Chambard J-C, Touboul T, Roux D, Pouysségur J, Pagès G. Extracellular signal-regulated kinases phosphorylate mitogen-activated protein kinase phosphatase 3/DUSP6 at serines 159 and 197, two sites critical for its proteasomal degradation. Mol Cell Biol. 2005; 25:854-64. doi: 10.1128/MCB.25.2.854-864.2005.

43. Lee M-Y, Chou C-Y, Tang M-J, Shen M-R. EpithelialMesenchymal Transition in Cervical Cancer: Correlation with Tumor Progression, Epidermal Growth Factor Receptor Overexpression, and Snail Up-Regulation. Clin Cancer Res. 2008; 14:4743-50.

44. Bae YS, Kang SW, Seo MS, Baines IC, Tekle E, Chock $\mathrm{PB}$, Rhee SG. Epidermal growth factor (EGF)-induced generation of hydrogen peroxide. Role in EGF receptormediated tyrosine phosphorylation. J Biol Chem. 1997; 272:217-21.

45. Liebmann C. Regulation of MAP kinase activity by peptide receptor signalling pathway: Paradigms of multiplicity. Cell Signal. 2001; 13:777-85. doi: 10.1016/ S0898-6568(01)00192-9.

46. Belousov V V, Fradkov AF, Lukyanov KA, Staroverov DB, Shakhbazov KS, Terskikh A V, Lukyanov S. Genetically encoded fluorescent indicator for intracellular hydrogen peroxide. Nat Methods. 2006; 3:281-6. doi: 10.1038/ nmeth866.

47. Dugina V, Khromova N, Rybko V, Blizniukov O, Shagieva G, Chaponnier C, Kopnin B, Kopnin P. Tumor promotion by $\gamma$ and suppression by $\beta$ non-muscle actin isoforms. Oncotarget. 2015; 6:14556-71. doi: 10.18632/ oncotarget.3989.

48. Kalluri R, Neilson EG. Epithelial-mesenchymal transition and its implications for fibrosis. J Clin Invest. American Society for Clinical Investigation; 2003; 112:1776-84. doi: 10.1172/JCI20530. 
49. Luo J, Lubaroff DM, Hendrix MJ. Suppression of prostate cancer invasive potential and matrix metalloproteinase activity by E-cadherin transfection. Cancer Res. 1999; 59:3552-6.

50. Hsu MY, Meier FE, Nesbit M, Hsu JY, Van Belle P, Elder DE, Herlyn M. E-cadherin expression in melanoma cells restores keratinocyte-mediated growth control and down-regulates expression of invasion-related adhesion receptors. Am J Pathol. 2000; 156:1515-25. doi: 10.1016/ S0002-9440(10)65023-7.

51. Smith BN, Burton LJ, Henderson V, Randle DD, Morton DJ, Smith BA, Taliaferro-Smith L, Nagappan P, Yates C, Zayzafoon M, Chung LWK, Odero-Marah VA. Snail promotes epithelial mesenchymal transition in breast cancer cells in part via activation of nuclear ERK2. PLoS One. 2014; 9: e104987. doi: 10.1371/journal.pone.0104987.

52. Schrevel M, Gorter A, Kolkman-Uljee SM, Trimbos JBMZ, Fleuren GJ, Jordanova ES. Molecular mechanisms of epidermal growth factor receptor overexpression in patients with cervical cancer. Mod Pathol. 2011; 24:720-8. doi: 10.1038/modpathol.2010.239.

53. Giorgio M, Migliaccio E, Orsini F, Paolucci D, Moroni M, Contursi C, Pelliccia G, Luzi L, Minucci S, Marcaccio M, Pinton P, Rizzuto R, Bernardi P, et al. Electron transfer between cytochrome $\mathrm{c}$ and $\mathrm{p} 66 \mathrm{Shc}$ generates reactive oxygen species that trigger mitochondrial apoptosis. Cell. 2005; 122:221-33. doi: 10.1016/j.cell.2005.05.011.

54. Frijhoff J, Dagnell M, Augsten M, Beltrami E, Giorgio $\mathrm{M}$, Östman A. The mitochondrial reactive oxygen species regulator p66Shc controls PDGF-induced signaling and migration through protein tyrosine phosphatase oxidation. Free Radic Biol Med. 2014; 68:268-77. doi: 10.1016/j. freeradbiomed.2013.12.022.

55. Galimov ER, Chernyak B V, Sidorenko AS, Tereshkova A V, Chumakov PM. Prooxidant properties of p66shc are mediated by mitochondria in human cells. PLoS One. 2014; 9: e86521. doi: 10.1371/journal.pone.0086521.

56. Maillet M, Purcell NH, Sargent MA, York AJ, Bueno OF, Molkentin JD. DUSP6 (MKP3) null mice show enhanced ERK1/2 phosphorylation at baseline and increased myocyte proliferation in the heart affecting disease susceptibility. J Biol Chem. American Society for Biochemistry and Molecular Biology; 2008; 283:31246-55. doi: 10.1074/jbc. M806085200.

57. Chan DW, Liu VWS, Tsao GSW, Yao K-M, Furukawa T, Chan KKL, Ngan HYS. Loss of MKP3 mediated by oxidative stress enhances tumorigenicity and chemoresistance of ovarian cancer cells. Carcinogenesis. 2008; 29:1742-50. doi: 10.1093/carcin/bgn167.

58. Wilson LA, Gemin A, Espiritu R, Singh G. ets-1 is transcriptionally up-regulated by $\mathrm{H} 2 \mathrm{O} 2$ via an antioxidant response element. FASEB J. 2005; 19:2085-7. doi: 10.1096/ fj.05-4401fje.

59. Lee K, Nelson CM. New insights into the regulation of epithelial-mesenchymal transition and tissue fibrosis. Int Rev Cell Mol Biol. 2012; 294:171-221. doi: 10.1016/ B978-0-12-394305-7.00004-5.

60. Suyama K, Shapiro I, Guttman M, Hazan RB. A signaling pathway leading to metastasis is controlled by N-cadherin and the FGF receptor. Cancer Cell. 2002; 2:301-14.

61. Nieman MT, Prudoff RS, Johnson KR, Wheelock MJ. $\mathrm{N}$-cadherin promotes motility in human breast cancer cells regardless of their E-cadherin expression. J Cell Biol. 1999; 147:631-44.

62. Bachran D, Schneider S, Bachran C, Urban R, Weng A, Melzig MF, Hoffmann C, Kaufmann AM, Fuchs H. Epidermal growth factor receptor expression affects the efficacy of the combined application of saponin and a targeted toxin on human cervical carcinoma cells. Int $\mathrm{J}$ cancer. 2010; 127:1453-61. doi: 10.1002/ijc.25123.

63. Mani SA, Guo W, Liao M-J, Eaton EN, Ayyanan A, Zhou AY, Brooks M, Reinhard F, Zhang CC, Shipitsin M, Campbell LL, Polyak K, Brisken C, et al. The epithelialmesenchymal transition generates cells with properties of stem cells. Cell. 2008; 133:704-15. doi: 10.1016/j. cell.2008.03.027.

64. Li X, Lewis MT, Huang J, Gutierrez C, Osborne CK, Wu M-F, Hilsenbeck SG, Pavlick A, Zhang X, Chamness GC, Wong H, Rosen J, Chang JC. Intrinsic resistance of tumorigenic breast cancer cells to chemotherapy. J Natl Cancer Inst. 2008; 100:672-9. doi: 10.1093/jnci/djn123.

65. Farmakovskaya M, Khromova N, Rybko V, Dugina V, Kopnin B, Kopnin P. E-Cadherin repression increases amount of cancer stem cells in human A549 lung adenocarcinoma and stimulates tumor growth. Cell Cycle. 2016; 15:1084-92. doi: 10.1080/15384101.2016.1156268.

66. Pattabiraman DR, Bierie B, Kober KI, Thiru P, Krall JA, Zill C, Reinhardt F, Tam WL, Weinberg RA. Activation of PKA leads to mesenchymal-to-epithelial transition and loss of tumor-initiating ability. Science. 2016; 351: aad3680. doi: 10.1126/science.aad3680. 